Nig J. Biotech. Vol. 31 (2016) 59-65

ISSN: 01891731

Available online at

http://www.ajol.info/index.php/njb/index

and www.biotechsocietynigeria.org

DOI: http://dx.doi.org/10.4314/njb.v31i1.8

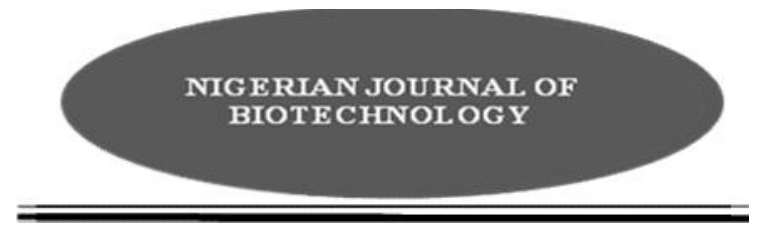

\title{
Numerical and RAPD Analysis of Eight Cowpea Genotypes from Nigeria
}

\author{
I dehen, E.O. ${ }^{1}$, Oyelakin, S.A. ${ }^{2}$, Onikola, A.O. ${ }^{1}$ and Adedapo, V.O. ${ }^{1}$ \\ ${ }^{1}$ Department of Plant Breeding and Seed Technology, Federal University of Agriculture, Abeokuta, \\ P.M.B. 2240, Abeokuta-Nigeria. ${ }^{2}$ Department of Pure and Applied Botany, Federal University of \\ Agriculture, Abeokuta, P.M.B. 2240, Abeokuta-Nigeria
}

(Received: 17:03:2016; Accepted: 04:07:2016)

\begin{abstract}
Cowpea, Vigna unguiculata (L.) Walp is one of the world's main legumes and is an important source of plant protein in human diet as well as a good cover crop. The wealth of any germplasm is measured in terms of the genetic variability. Hence, numerical tools such as single linkage cluster analysis (SLCA) and principal component analysis (PCA) have been used to determine the extent of variability. This study was conducted to determine the performance, character contribution as well as variation pattern in eight cowpea genotypes collected in Nigeria. Field evaluations were carried out in June and September, 2015 and also molecular studies. Data collected were subjected to analysis of variance and Duncan's multiple range test was used to separate significant means at $5 \%$ probability level. Molecular data were subjected to NTSYS-pc software. Genotype IT98K-573-1-1 had the highest 100 -seed weight $(26.06 \mathrm{~g})$ and seed weight per plant $(36.00 \mathrm{~g})$. The first three PCA had eigen values greater than one and accounted for $75.48 \%$ cumulative variance. Pod length, 100-seed weight and seed weight per plant contributed significantly to the overall variation observed in the genotypes. The agro-morphological and molecular dendrograms grouped the genotypes into four and three groups, respectively with genotype IT98K-573-11 clearly distinguished by the molecular dendrogram. Knowledge of the character contribution as well as variation pattern will assist plant breeders in the choice of parents for hybridization in future breeding programmes.
\end{abstract}

Key words: cowpea, genotype, dendrogram, PCA, SLCA

Correspondence: emmaidehen@yahoo.com, ideheneo@funaab.edu.ng

\section{Introduction}

Cowpea, Vigna unguiculata (L.) Walp is one of the world's main legumes (Pasquet \& Baudoin, 1997). It is well adapted to drier regions of the Tropics where other food legumes do not perform well. It also has the ability to fix atmospheric nitrogen through its root nodules, and grows well in poor soil more than $85 \%$ sand and less than $0.2 \%$ organic matter with low levels of phosphorus. Cowpea production in Africa represents $91 \%$ of the global production. West Africa has 9.5 million hectares cultivated which accounts for most of Africa's production, with Nigeria accounting for 3.2 million hectares (FAO, 2013). The wealth of any germplasm is measures in terms of genetic variability. Thus, numerical tools have been used by researchers to determine the extent of variability. Principal Component Analysis (PCA) determines character contribution to overall variation and its discriminating power is based on the strength of the axis as measured by their eigen values. The Single Linkage Cluster Analysis (SLCA), an agglomerative technique cluster materials based on their similarity coefficients. Molecular analysis such as Randomly Amplified Polymorphism DNA (RAPD) has an advantage in genome analysis in that no prior sequence knowledge is required, use of small amounts of DNA, it is simple to carry out and its detection is not radioactive (Wolfe $\&$ Liston, 1998). The objectives of this research was to determine the individual character contribution to the overall variability as well as the relatedness of 
the eight cowpea genotypes based on agromorphological and RAPD techniques.

\section{Materials and Methods}

Plant Materials: Eight cowpea genotypes used in this study were sourced from the gene bank of International Institute of Tropical Agriculture (IITA), Ibadan, Nigeria (Table 1).

Table 1. List and source of the genotypes used in this study.

\begin{tabular}{ll}
\hline Varieties & \multicolumn{1}{c}{ Source } \\
\hline IT07K-243-1-2 & IITA, I badan, Nigeria \\
IT98K-573-1-1 & IITA, I badan, Nigeria \\
IT99K-529-2 & IITA, I badan, Nigeria \\
IT07K-210-1-1 & IITA, I badan, Nigeria \\
ITO7K-299-6 & IITA, I badan, Nigeria \\
UAM-1055-6 & IITA, I badan, Nigeria \\
UAM-1056-2 & IITA, I badan, Nigeria \\
IT07K-298-15 & IITA, I badan, Nigeria \\
\hline
\end{tabular}

- IITA- International Institute of Tropical Agriculture

Agro-morphological studies: Field evaluations of the genotypes were carried out at the Directorate of University Farms, Federal University of Agriculture, Abeokuta, Nigeria in two seasons (J une and September, 2015). The experiments were laid out in a randomized complete block design with three replications. Data was collected on the following agronomic characters: number of days to emergence, number of days to flowering, number of days to podding, petiole length $(\mathrm{mm})$, pod length $(\mathrm{mm})$, 100-seed weight $(\mathrm{g})$ and seed weight per plant (g). Data collected on agronomic characters were pooled and subjected to statistical analysis using SAS/PC version 8.0 (SAS Institute, 1999) and significant means were separated using Duncan's Multiple Range Test. Principal Component Analysis (PCA) and Single Linkage Cluster Analysis (SLCA) were utilized to determine the variation pattern in the accessions.

Molecular Studies: Genomic DNA was extracted from the leaves of 10-14 days old seedlings using the plant DNA extraction kit from NORGEN Biotek Corporation. The nucleic acid concentration $(n g / \mu l)$ was determined using the Nanodrop spectrophotometer. Agarose gel electrophoresis was carried out to determine the
DNA quality. The genomic DNA was used in PCR amplification using 22 RAPD primers (Table 2 ).

Table 2. List and sequence of RAPD primers used in this study

\begin{tabular}{lll}
\hline S/N & Primer name & Sequence \\
\hline 1 & OPB-10 & CTGCTGGGAC \\
2 & OPB-11 & GTAGACCCGT \\
3 & OPB-12 & CCTTGACGCA \\
4 & OPB18 & CCACAGCAGT \\
5 & OPC-07 & GTCCCGACGA \\
6 & OPC-13 & AAGCCTCGTC \\
7 & OPD-02 & GGACCCAACC \\
8 & OPD-07 & TTGGCACGGG \\
9 & OPD-11 & AGCGCCATTG \\
10 & OPD-16 & AGGGCGTAAG \\
11 & OPE-06 & AAGACCCCTC \\
12 & OPE-09 & CTTCACCCGA \\
13 & OPE-12 & TTATCGCCCC \\
14 & OPE-18 & GGACTGCAGA \\
15 & OPF-13 & GGCTGCAGAA \\
16 & OPF-19 & CCTCTAGACC \\
17 & OPG-09 & CTGACGTCAC \\
18 & OPG-11 & TGCCCGTCGT \\
19 & OPH-11 & CTTCCGCAGT \\
20 & OPH-18 & GAATCGGCCA \\
21 & OPT-02 & GGAGAGACTC \\
22 & OPT-04 & CACAGAGGGA \\
\hline
\end{tabular}

The reaction mix was carried out in $20 \mu \mathrm{l}$ final volume containing $60 \mathrm{ng}-80 \mathrm{ng}$ genomic DNA, $0.1 \mu \mathrm{M}$ of the primers, $2 \mathrm{mM} \mathrm{MgCl}, 125 \mu \mathrm{M}$ of each dNTP and 1 unit of Taq DNA polymerase. The thermocycler profile was an initial denaturation temperature for 3 mins at $94^{\circ} \mathrm{C}$, followed by 45 cycles of denaturation temperature at $94^{\circ} \mathrm{C}$ for 20 seconds, annealing at $37^{\circ} \mathrm{C}$ for 40 seconds and primer extension at $72^{\circ} \mathrm{C}$ for 40 seconds, followed by final extension temperature at $72^{\circ} \mathrm{C}$ for 5 mins was added. PCR amplicon electrophoresis was carried out by size fractionation on $2.0 \%$ agarose gels at $100 \mathrm{~V}$ for 2 hours. The DNA was visualized and photographed under UV light source. Bands were scored in the binary mode with ' 1 ' indicating the presence and ' 0 ' indicating the absence of $a$ band. The excel file containing the binary data was imported into NTSYS-pc 2.02J (Rohlf, 2000) and dendrograms were drawn using the similarity matrix. In addition, PCA based clustering was also done using the subroutine eigen. 


\section{Results}

The pooled mean performance of the eight cowpea genotypes is presented in Table 3. The genotypes were not statistically different for most of the characters evaluated except for days to flowering, pod length and yield per plant. The yield for IT98K-573-1-1 was relatively high (36.00g/plant) while that for IT99K-529-2 was low $(17.00 \mathrm{~g} /$ plant). The three principal components had eigen values greater than one (Table 4) and these accounted for 33.30, 29.31 and $12.86 \%$ of the total variation individually and $75.48 \%$ cumulatively. The relative discriminating power of the axes as indicated by the eigen values was high (2.99) for the first axis and low for the third axis (1.15). Characters loading the first axis include; pod length, 100-seed weight and seed weight/plant. Number of days to emergence, number of days to flowering and petiole length mainly loaded the second axis while the third axis was loaded mainly with number of days to podding.

Table 3. Pooled mean performance of the eight cowpea genotypes evaluated in this study

\begin{tabular}{|c|c|c|c|c|c|c|c|}
\hline Varieties & $\begin{array}{l}\text { Number of } \\
\text { days to } \\
\text { emergence }\end{array}$ & $\begin{array}{l}\text { Number } \\
\text { of days to } \\
\text { flowering }\end{array}$ & $\begin{array}{l}\text { Number } \\
\text { of days to } \\
\text { podding }\end{array}$ & $\begin{array}{l}\text { Petiole } \\
\text { length } \\
(\mathrm{cm})\end{array}$ & $\begin{array}{l}\text { Pod } \\
\text { length } \\
(\mathrm{cm})\end{array}$ & $\begin{array}{l}\text { 100- seed } \\
\text { weight } \\
\text { (g) }\end{array}$ & $\begin{array}{l}\text { Seed } \\
\text { yield/ } \\
\text { plant }(\mathrm{g})\end{array}$ \\
\hline IT07K-243-1-2 & $5.33 a$ & $47.00 \mathrm{~b}$ & $51.33 b$ & $5.16 b$ & $3.06 c$ & $19.05 b$ & $24.67 a b c$ \\
\hline IT98K-573-1-1 & $6.33 a$ & $47.67 b$ & $54.67 a b$ & $4.43 b$ & 7.36a & $26.06 a$ & $36.00 a$ \\
\hline IT99K-529-2 & $5.33 a$ & $51.00 a b$ & $58.00 a$ & $4.33 b$ & 5.30abc & $14.26 \mathrm{~d}$ & $17.00 \mathrm{C}$ \\
\hline IT07K-210-1-1 & $6.66 a$ & $48.00 b$ & $57.67 a$ & $5.36 b$ & $6.00 a b$ & $14.10 \mathrm{~d}$ & $19.33 b c$ \\
\hline IT07K-299-6 & $5.33 a$ & $52.66 a$ & $50.33 b$ & $8.53 a$ & $5.66 a b$ & $16.55 c$ & $26.00 \mathrm{abc}$ \\
\hline UAM-1055-6 & $5.33 a$ & $47.00 \mathrm{~b}$ & $53.00 a b$ & $9.03 a$ & $3.90 \mathrm{bc}$ & $11.50 \mathrm{e}$ & $19.33 b c$ \\
\hline UAM-1056-2 & $5.00 a$ & $50.33 a b$ & $52.67 a b$ & $7.00 \mathrm{ab}$ & $3.10 \mathrm{c}$ & $12.00 \mathrm{e}$ & $29.66 a b$ \\
\hline IT07K-298-15 & $6.33 a$ & $51.00 a b$ & $49.67 b$ & $6.60 a b$ & $3.23 c$ & $16.60 c$ & $19.33 b c$ \\
\hline
\end{tabular}

$*$ Means followed by the same alphabet along columns are not statistically different from each other at $5 \%$ probability level.

Table 4. Eigen value, variance and cumulative percentage variance of the first three principal component of the pooled characters evaluated in the two seasons

\begin{tabular}{llll}
\hline Characters & Axis 1 & Axis 2 & Axis 3 \\
\hline No. of days to emergence & -0.01 & 0.33 & -0.28 \\
No. of days to flowering & 0.01 & 0.31 & 0.50 \\
No. of days to podding & 0.17 & 0.20 & 0.54 \\
Petiole length (cm) & 0.03 & -0.27 & 0.38 \\
Pod length (cm) & -0.23 & 0.14 & -0.14 \\
100-seed weight (g) & 0.27 & 0.03 & -0.11 \\
Seed weight/plant (g) & 0.28 & 0.09 & -0.16 \\
Eigen value & 2.99 & 2.63 & 1.15 \\
Variance (\%) & 33.30 & 29.31 & 12.86 \\
Cummulative variance (\%) & 33.30 & 62.62 & 75.48 \\
\hline
\end{tabular}

Dendrograms resulting from single linkage clustering analysis for the agro-morphological and molecular data are presented in Figures 1 and 2, respectively. 


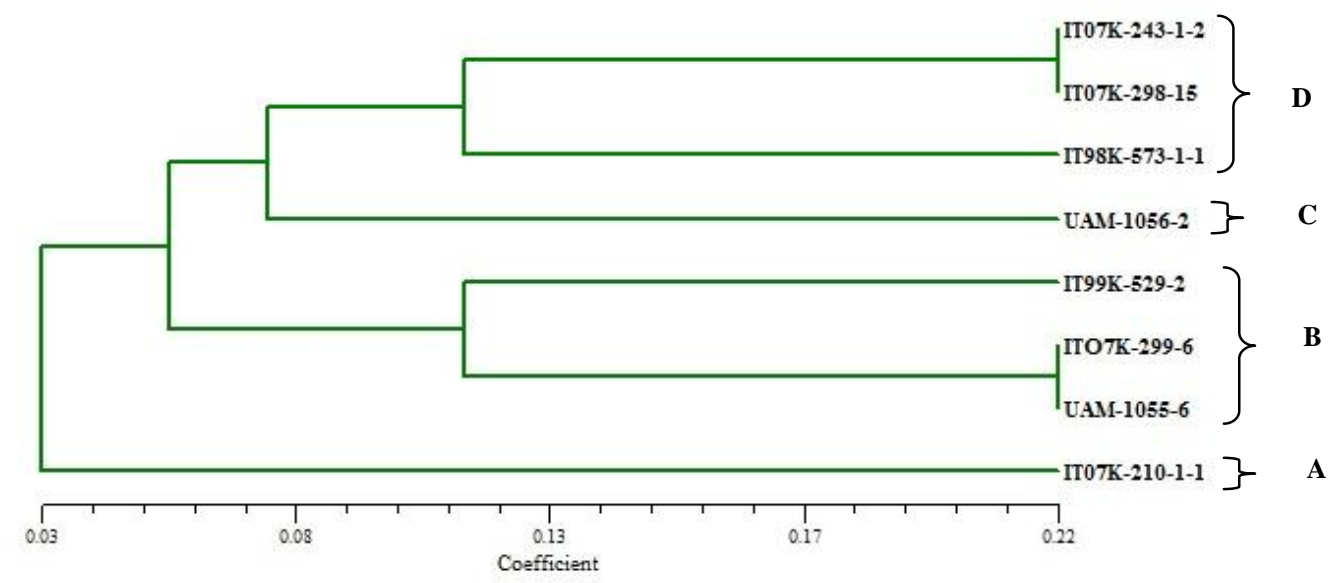

Figure 1. Dendrogram resulting from pooled agro-morphological analysis showing similarity coefficients for the eight genotypes of cowpea used in this study

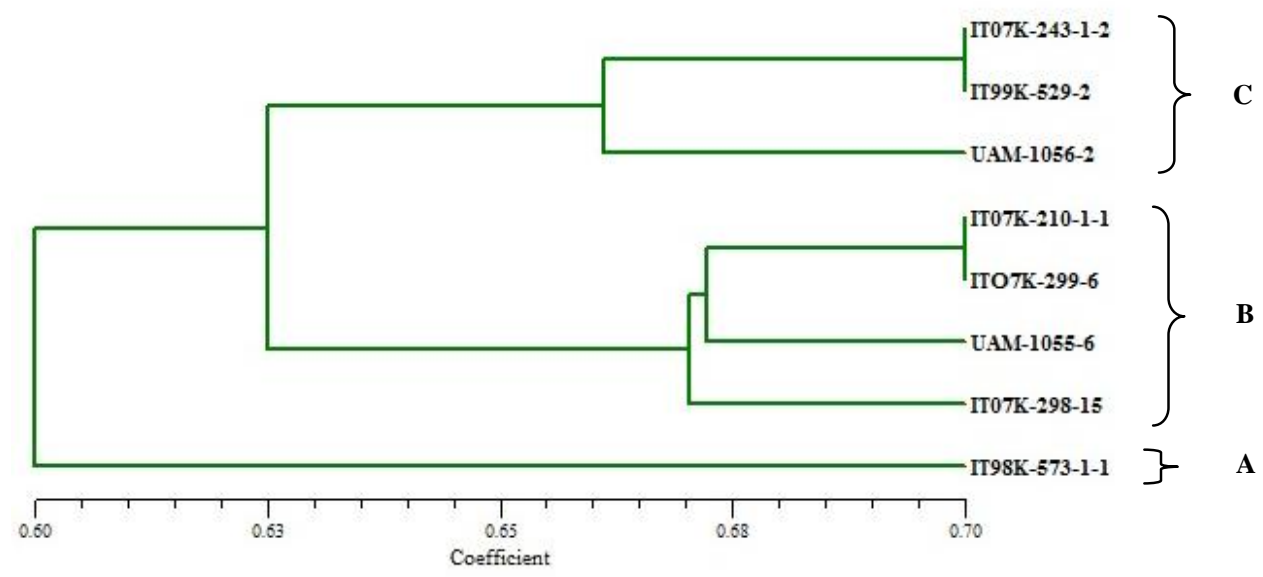

Figure 2. Dendrogram resulting from RAPD analysis showing similarity coefficients for the eight genotypes of cowpea used in this study

Similarity coefficients for the agromorphological dendrogram ranged from 0.03 0.22 , while that of the molecular analysis ranged from $0.60-0.70$. The agro-morphological dendrogram separated the accessions into four groups with group A (IT07K-210-1-1) and group C (UAM-1056-2) having only one accession each. Though, at a coefficient of 0.22 , two genotypes in groups B (ITO7K-299-6 and UAM-1055-6) and D (IT07K-243-1-2 and IT07K-298-15) could not be clearly distinguished. The molecular dendrogram grouped the genotypes into three groups, with genotype IT98K-573-1-1 belonging only to group A. Group B had the highest number of accessions cluster (four) though (IT07K-299-6 and IT07K210-1-1) were not distinguishable even at a coefficient of 0.70 . while the remaining accessions (3) were clustered in group $C$. The two dimensional plots in Figures 3 and 4 showed a similar trend to that of the dendrograms. 


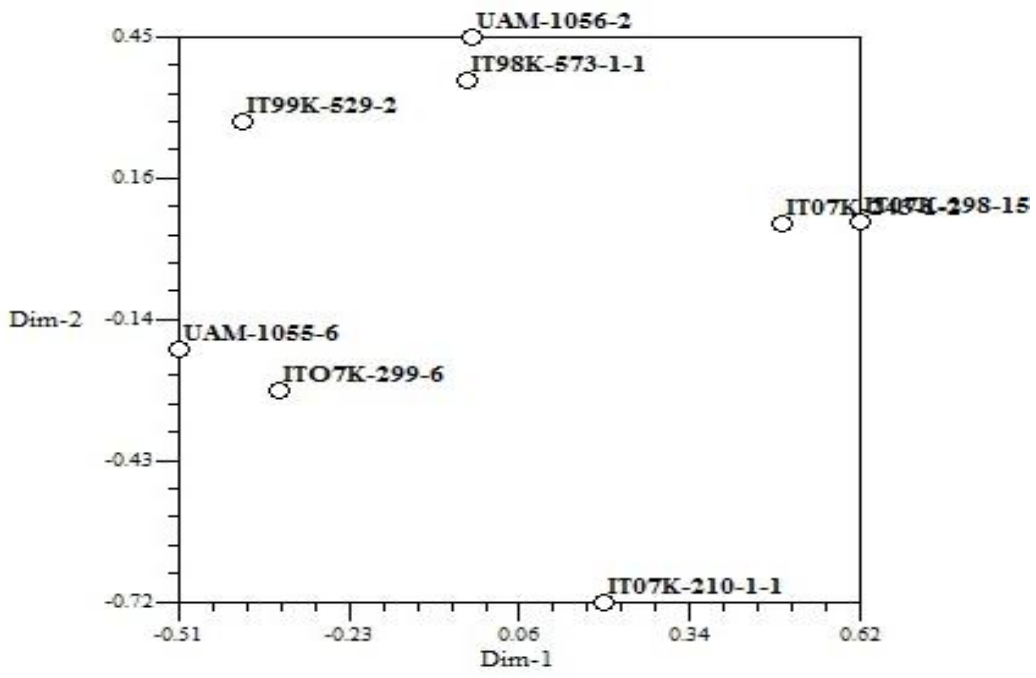

Figure 3. Two-dimensional plots of the eight genotypes of cowpea based on pooled agromorphological characters

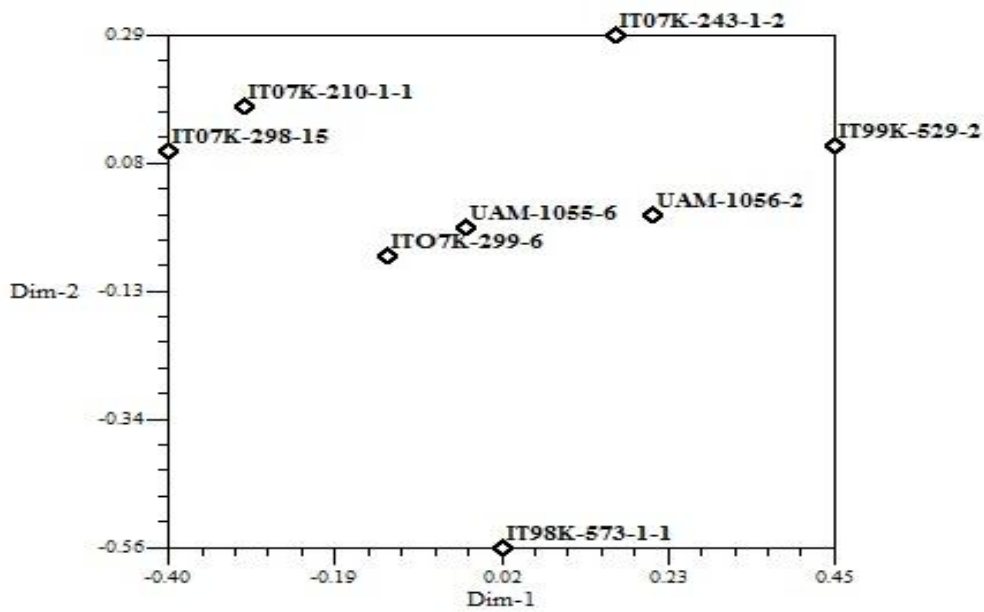

Figure 4. Two-dimensional plots of the eight genotypes of cowpea based on

$$
\text { RAPD analysis }
$$

\section{Discussion}

Mean performance of the genotypes evaluated showed significant variation existing among the cowpea genotypes especially with respect to pod length, 100-seed weight and seed yield per plant. The highest 100-seed weight and yield was recorded for genotype IT98K-573-1-1. Scores of the characters describing the three axes as revealed by the PCA confirmed the co-variation among the genotypes evaluated. It also reveals character contributing most to the overall variation observed within a group of entries (Ogunbodede, 1997). Characters in the first axis, such as 100 seed weight and seed weight per plant were the most important discriminants in the cowpea genotypes evaluated because of the importance of this axis which has the highest eigen value. The biological implication of principal components can be assessed from contribution of the different variables to each component from their eigen vectors (Lezzoni \& Pritts, 1991). The second axis which also have a closely related eigen value to the first, showed number of days to emergence and flowering as the next most important discriminant in the cowpea genotypes. Number of days to flowering has also been found to be an important criterion for grouping genotypes as it is always correlated with life span of plants (Sneath \& Sokal, 1973 and Ariyo, 1993).

Cluster analysis has been reported to have the singular efficacy and ability to identify crop genotypes with highest level of similarities using 
the dendrogram (Aliyu \& fawole, 2000). The single linkage cluster analysis, which is the distance between two clusters is determined by a single element pair, namely those two elements (one in each pair) that are closest to each other. The shortest of these links that remains at any step causes the fusion of the two clusters whose elements are involved (Legendre \& Legendre, 1998). Agro-morphological dendrogram grouped the genotypes into four groups, showing the distinction of genotypes IT07K-210-1-1 and UAM1056-2 and this was characteristic of their short pod length. But molecular dendrogram reordered the genotypes into three distinct groups with genotype IT98K-573-1-1 clearly distinguished from all others. This genotype was characterized by long pod length, high 100-seed weight and seed yield. Genotype IT07K-299-6 in group 2 of the molecular dendrogram was characterized by late flowering, though the long petiole length could be the likely cause for the delay in flowering because of the long transition from the vegetative to the reproductive stage. The two dimension plots, further reveals the spatial distinctions of the genotypes as similar trends were observed as that of the single linkage cluster analysis.

The use of agro-morphological classification to access genetic variation is less expensive compared to molecular approach, but the former could be influenced by environmental and genetic factors leading to interactions between the genotype and the environment. In addition, morphological markers may present an altered phenotype that interferes with the growers' needs, therefore difficult to identify true genetic similarity or variation. In order to overcome these problems, molecular techniques such as the RAPD which is quick, easy and less expensive have been adopted to determine genetic variability (Asemota et al., 1996). However, if SSR primers are used opposed to RAPD primers, the clustering would differ because the former (SSR) identifies specific loci thus revealing higher levels of polymorphism, while the latter randomly amplifies the loci and the results are not reproducible (Pejic et al., 1998, Idehen et al., 2014)

\section{Conclusion}

The cowpea genotypes evaluated revealed IT98K-573-1-1 as being a high yielder, whereas IT99K-529-2 as a low yielder. Number of days to emergence, number of days to flowering, 100- seed weight and seed yield were the most significant discriminants for the genotypes as shown by their character contributions to the overall variation. The agro-morphological and molecular dendrograms grouped the genotypes into four and three groups, respectively, with the molecular dendrogram clearly showing the distinction of IT98K-573-1-1 from all other genotypes. And this genotype was characterized with long pods, high 100-seed weight as well as high seed yield. It is also important to note the superiority of molecular approach of classification when compared to agro-morphological because the former is not affected by environmental factors. This study revealed that hybridization could be made by selecting members from distant groups in order to take advantage of their variability.

\section{Aknowledgements}

The authors are grateful to International Institute of Tropical Agriculture (IITA), Ibadan, Nigeria for provision of the cowpea genotypes. Directorate of University Farms (DUFARMS), Federal University of Agriculture, Abeokuta, Nigeria, where the field evaluations were carried out and Biotechnology Centre, Federal University of Agriculture, Abeokuta, Nigeria for molecular study.

\section{References}

Aliyu, B. and Fawole, I. (2000). Inheritance of pubescence in crosses between Vigna unguiculata and V. rhomboidea. Nigerian Journal of Genetics 15:9-14

Ariyo, O. J. (1993). Genetic diversity in West Africa okra ( Abelmoschus Caillei (A chev) StevelsMultivariate analysis of morphological and agronomic characteristics. Genetics Res. and Crop Evolution 40: 25 - 32

Asemota, H. N., Ramser, J., Lopez-Peralta, C., Weising, K. and Kahl, G. (1996). Genetic variation and cultivar identification of Jamaican yam germplasm by random amplified polymorphic DNA analysis. Euphytica 92: 341 - 351.

Idehen, E. O., Kehinde, O. B., Wang, X. and Oyelakin, O. O. (2014). Discriminating Nigerian 'egusi' melon accessions using Agro-morphological 
and molecular techniques. Nigerian Journal of Biotechnology 28: 1 - 10

Food and Agricultural Organization of the United Nations (2013). FAO Year book production. FAO, Rome, Italy.

Legendre, P. and Legendre, L. (1998). Numerical Ecology. Second English Edition, p.853.

Ogunbodede, B. A. (1997). Multivariate analysis of genetic diversity in kenaf (Hibiscus cannabinus (L.) African Crops Science J. 5, 2:127-133.

Lezzoni, A. F. and Pritts, M. P. (1991). Application of principal component analysis to horticultural research. Hort. Science 26 (4): 334-338

Pasquet, R. S. and Baudoin, J. P. (1997). Cowpea In: Tropical Plant Breeding. CIRAD. Paris pp 177 198.
Pejic, I., Ajmone-Marsan, P., Morgante, M., Kozumplick, V., Castiglioni, P., Taramino, G. and Motto, M. (1998). Comparative analysis of genetic similarity among maize inbred lines detected by RFLPs, RAPDs, SSRs, and AFLPs. Theoretical Applied Genetics 97: 1248-1255.

Rohlf, F. J. (2000). NTSYS-pc: Numerical Taxonomy and Multivariate Analysis System, version 2.1. Exeter Software, Setauket, New York

Statistical Analysis System (1999). Statistical Methods. SAS Institute Inc. Cary North Carolina.

Sneath, P. M. and Sokal, R. P. (1973). Numerical Taxonomy. The principle and practice of numerical classification. San Francisco WH Freeman p.573.

Wolfe, A. D. and Liston, A. (1998). Contributions of PCR-based methods to plant systematics and evolutionary biology. In Soltis, D.E. Soltis, P.S. and Doyle, J.J. (eds.). Molecular Systematics of Plants: DNA Sequencing, $2^{\text {nd }}$ Ed. Kluwer Academic, Boston. Pp. 43-86. 